American Journal of Environmental Sciences 2 (4): 146-153, 2006

ISSN 1553-345X

(C) 2006 Science Publications

\title{
A Near Real-time Early Warning System on Erosion Hazards
}

\author{
${ }^{1}$ Faisal $\mathrm{Hj}$. Ali and ${ }^{2}$ Tew Kia Hui \\ ${ }^{1}$ Civil Engineering Department, Faculty of Engineering, University of Malaya. Kuala Lumpur, Malaysia \\ ${ }^{2}$ VT Soil Erosion Research and Consultancy, 9 Jalan Akasia 1, Saujana Akasia \\ Sg. Buloh, Selangor, Malaysia
}

\begin{abstract}
With many incidences of landslides, mudslides and erosion occurrences lately, especially in the highlands in Malaysia, properties were damaged and lives were lost. Seeing the need of resolving and minimizing such untoward incidences, a study has been embarked on developing a near real-time early warning system on erosion hazards so as to provide an early warning to the public, whenever there are signs and probable occurrence of such incidences. Consequently, a case study on Cameron Highlands Catchment was carried out, which involved a detailed baseline database of the study area to be set up first. The highland catchment is considered an environmentally sensitive area where many land development for various activities such as agriculture, agro-tourism, property development and roadwidening projects, had already been carried out and some are still on going as to-date. To develop the baseline database, acquisition of the latest Structure Plan, Satellite Imagery, topographical and rainfall information of the catchment area were carried out. Once this is done, real-time rainfall information would be adopted to develop the early warning system. This could be done by using solar-powered rain sensors, which would be triggered based on the rainfall amount and intensity. A SIM-card based GPRS transmitter, which is attached to the "rain sensing and transmission unit" would then send out e-mails at every minute interval, so that the data could be transferred to a receiving unit. At this point, the e-mail is read and data is processed within the Geographical Information Systems (GIS) using an automated keyboard simulation programme. The final processed values would then be set against the threshold values, which will trigger an early warning if any of the values exceeds the threshold limits. Therefore, it is hoped that the application of this new locally developed system, which has been trademarked under the name EWARNS ${ }^{\mathrm{TM}}$ (Early Warning And Risk Navigation Systems), would be beneficial to the local authorities, highway operators and the public in general in providing an early warning especially during periods of heavy rainfall, which could possibly trigger serious soil erosion occurrences that may induce landslides.
\end{abstract}

Key word: Baseline database, early warning system, hazards, soil erosion, rainfall

\section{INTRODUCTION}

With respect to numerous erosion, landslide and mudslide occurrences in Malaysia recently, particularly at hillslopes and highlands, there are a great concern that these areas are extremely sensitive to disturbances of any sort. Events over the past years, such as landslides at the Genting Highlands slip road (1996 and 2004), the collapse of the Highland Tower (1993), landslide at Bukit Antarabangsa (1999), landslides and mudslides at Gua Tempurung (1996 and 2004), landslides at the KL - Karak Highway near Bentong (2003 and 2004), landslides and mudslides in Cameron Highlands (2000 and 2004) and minor landslides in Fraser's Hill occurring almost every year, have indicated what can happen when things go wrong. Seeing the need of resolving and minimizing such untoward incidences, a study has been embarked on developing a near real-time early warning system on erosion hazards so as to provide an early warning to the public, whenever there are signs and probable occurrence of such incidences. A case study on Cameron Highlands Catchment has been carried out, which involved a detailed baseline database of the study area to be set up first. This highland catchment is being considered an environmentally sensitive area where many land development activities such as agriculture, agro-tourism, property development and road-widening projects, had been carried out and some are still ongoing as to-date.

Malaysia, in its rapid progress of developing in line with Vision 2020, is undergoing tremendous land development, especially in the development of infrastructures. Although these activities form an integral part of the socio-economic advancement in this country, their success is indeed limited, if insufficient attention is paid to the adverse effects of land development, particularly on soil erosion issues ${ }^{[1]}$.

In engineering perspective, soil erosion is defined as a general destruction of soil structure by the action of

Corresponding Author: $\quad$ Dr. Tew Kia Hui, Director, VT Soil Erosion Research and Consultancy 9 Jalan Akasia 1, Saujana Akasia, 47000 Sg. Buloh, Selangor, Malaysia, Tel: +603 61575881 Fax: +603 61575887 
water and wind ${ }^{[2]}$. It is essentially the smoothing process with soil particles being carried away, rolled and washed down by the force of gravity ${ }^{[3]}$. Rainfall is the prime agent of soil erosion, whereby the rain's runoff will scour away, loosen and break soil particles and then carry them away, thus leaving behind an altered bare earth surface ${ }^{[4]}$. In the case of a slope, an altered bare surface of the slope with the formation of sheet, rill and gully erosion features will cause instability of the slope. This situation will gradually cause slope failure or landslide as commonly known. The soil erosion phenomenon is basically the function of the erosivity of the rainfall and the erodibility of the soil $^{[5]}$. In other words, when the rainfall acts upon the earth surface, the amount of the soil erosion loss will basically depend upon the combination of the strength and the magnitude of the rainfall to cause the erosion process and the ability of the soil to withstand the rain itself ${ }^{[6]}$.

The soil erosion-related problems could be identified and minimized if the knowledge of the soil erosion prone areas are identified and mapped. A near real-time early warning system on erosion hazards would provide vital information on this issue.

\section{Among the objectives of this study are:}

* To provide timely warning to the public and authorities via SMS Alerts, especially concerned and affected parties to take specific precaution whenever any warning of high risk areas is triggered;

* To provide information online 24 hours/day so that any member of the public with available Internet connectivity would be able to know the near realtime soil erosion hazards via the website;

* To identify the potential erosion hazards through its database acquisition and development, coupled with the real-time rainfall information so that site specific mitigation measures and emergency response plan could be undertaken, should there be any potential danger or threats on a specific area; and

* To carry out verification on past incidences of landslides or serious erosion occurrences by carrying out trial run simulations based on historical information to ensure that the predicted near real-time information is at an acceptable accuracy.

The development of an early warning system on erosion hazards is hoped to provide an early warning to the authorities, tourists, hoteliers, farmers and the public in general within the Cameron Highlands Catchment by monitoring the current situation there more closely including taking mitigative measures, should there be at any time specific locations within their jurisdiction proven to have high erosion hazards, which would possibly induce landslides. This could be done simply by just logging onto a website and checking out the situation of the roads, agricultural farms and specific built-up areas on the level of erosion hazards involved as information on these areas would be updated every minute should there be any rainfall event. Tourists and motorists heading to Cameron Highlands would also be well informed and be able to plan their travel better as such information would be updated constantly via the EWARNS ${ }^{\mathrm{TM}}$ website (www.ewarns.com.my). Farmers and hoteliers in Cameron Highlands would also be forewarned of the dangers involved and be able to take necessary measures to protect and safeguard their properties. Local authorities and relevant agencies would also be notified via SMS Alerts to take precautions and carry out inspections on high-risk areas when there are any incidences of continuous heavy downpour within a specified area. The scope of research and development for this study would include developing:

* Baseline database for the Cameron Highlands Catchment

* $\quad$ Rain sensing and transmission unit (RSTU)

* Receiving unit, which includes processing of near real-time data

* Early warning system panel, which would be hosted on the EWARNS ${ }^{\mathrm{TM}}$ website

The study area, Cameron Highlands Catchment is located within the Cameron Highlands district of 59,153 hectares $(146,171$ acres $)$. It comprises an area of $41,801.94$ acres, which could be sub-divided into five smaller sub-catchments, namely:

* Lower Bertam Catchment

* Upper Bertam Catchment

* Kial - Kodol Catchment

* Lower Telom Catchment

* Upper Telom Catchment

The 5 sub-catchments are shown in Fig. 1 and 3Dimensional View is as shown in Fig. 2.

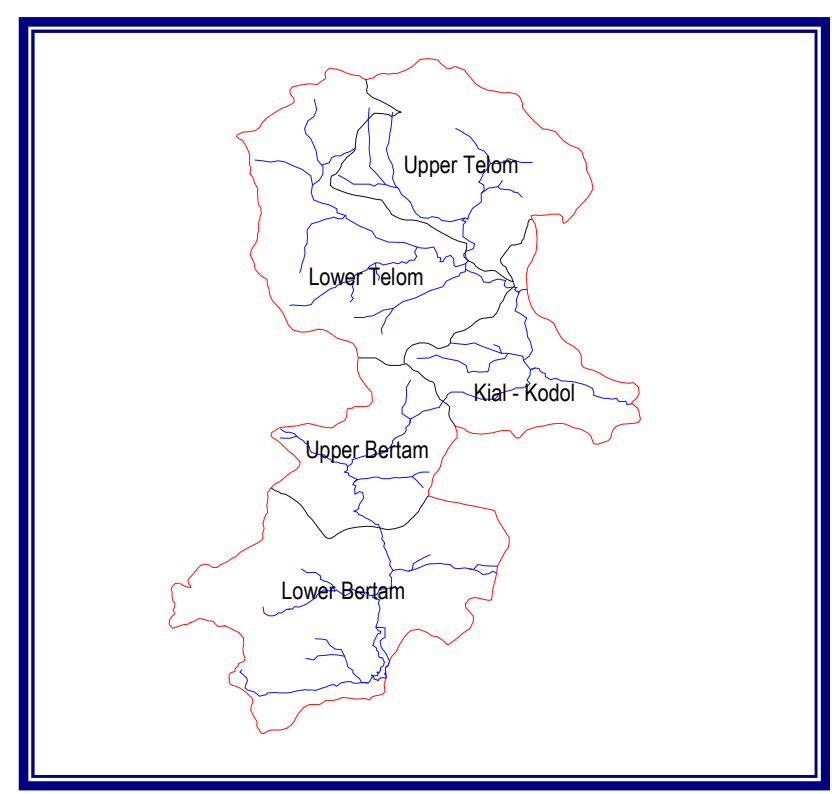

Fig. 1: Cameron highlands catchment 


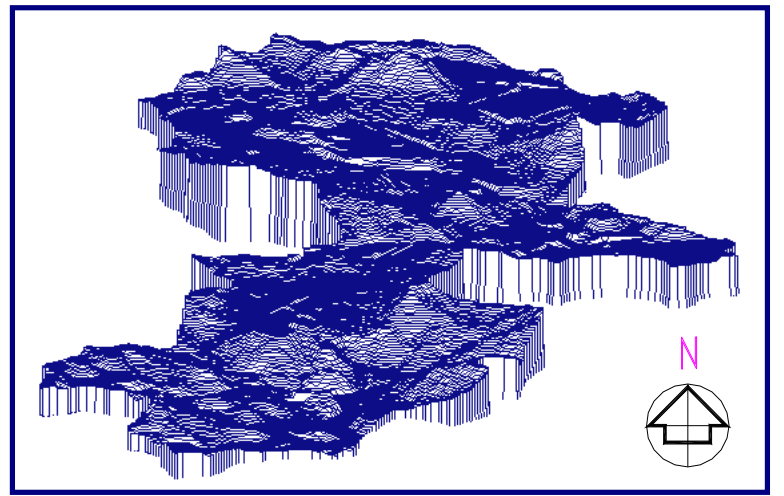

Fig. 2: 3-D view of Cameron highlands catchment

\section{METHODOLOGY}

Methodology of research for the development of the near real-time early warning system on erosion hazards is firstly the acquisition of baseline data for the study area, Cameron Highlands Catchment. Liaison with various agencies was required to obtain the relevant information, which include the latest Cameron Highlands Structure Plan (1995 - 2020), current land use using SPOT 4 Satellite Imagery dated $19^{\text {th }}$ April 2005, topographical information using Topographical Map (Sheet 74), and recorded rainfall information from nine existing rainfall stations within the catchment area. Such information would then be used for simulation of data for input into the early warning system.

Once this is completed, a prototype of actual realtime outdoor transmission unit is then developed as shown Fig. 3. This could be done using solar-powered rain sensors, which would be triggered based on the rainfall amount and intensity. A SIM-card based GPRS transmitter, which is attached to the interface module of the Rain Sensing and Transmission Unit (RSTU) would then send out e-mails / internet file transfers at every minute interval, so that the data could be transferred to a receiving unit (a server connected to high speed Internet line). At this point, the e-mail / transferred file is read and data is processed within the Geographical Information Systems (GIS) using an automated keyboard simulation programme. The final processed values would then be set against the threshold values, which will trigger an early warning if any of the values exceeds the threshold limits.

Subsequently, the early warning panel, which is also known as EWARNS ${ }^{\mathrm{TM}}$ Display Panel, would be up hosted to the website (www.ewarns.com.my), whereby such information would be made accessible to the public and authorities involved. The website's map of erosion risk areas will also be updated every minute as data from the sensors are constantly calculated. A blinking red light with continuous playback of the 'warning' sound would indicate that a certain area is at high risk of erosion (>1.0 t/ha/day), while yellow is for medium $(0.51-1.0 \mathrm{t} / \mathrm{ha} / \mathrm{day})$ and blue for low risk

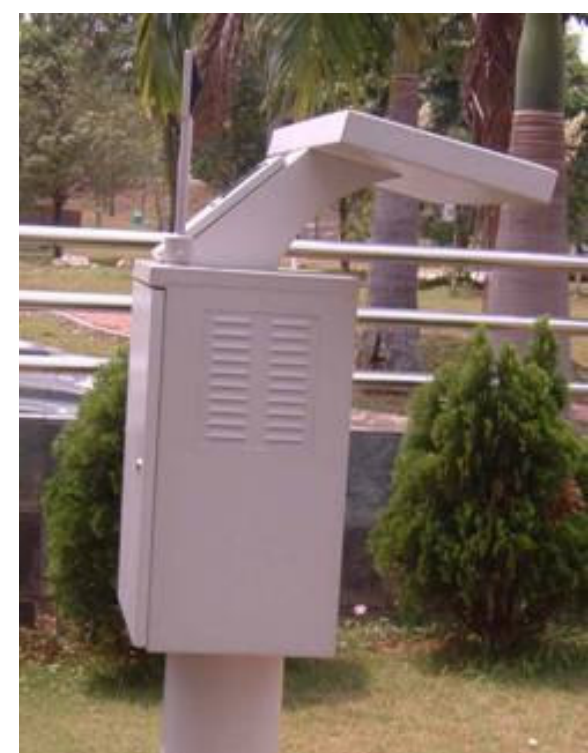

Fig. 3: EWARNS $^{\mathrm{TM}}$ outdoor Rain Sensing and Transmission Unit (RSTU)

locations $(0-0.5 \mathrm{t} / \mathrm{ha} / \mathrm{yr})$. Remarks on the percentage of risk area and in acreage for the built-up areas, roads and agricultural areas would also be shown in the display panel.

Flowchart showing the operation of the EWARNS $^{\mathrm{TM}}$ real-time early warning system on erosion hazards is as depicted in Fig. 4 and the graphical interpretation of the system's operational phase is also shown in Fig. 5. Subsequently, Fig. 6 shows the sample of EWARNS ${ }^{\mathrm{TM}}$ display panel and corresponding rainfall erosivity (Fig. 7) as viewed via the website.

Baseline data and the early warning system development: The gathering of baseline information was carried out for factors influencing soil erosion, which are based on the Universal Soil Loss Equation, (USLE). These factors would include the Rainfall Erosivity, R, Soil Erodibility, K, Slope Length and Steepness, LS and Land Use Management, CP. For Rainfall Erosivity, R, nine rainfall stations, which are located within the Cameron Highlands Catchment were taken into consideration. $\mathrm{R}$ factor values for the 9 stations were then interpolated to produce the R Factor Map. Soil Erodibility, K, is calculated based on the results of the "Hand Auger Soil Sampling" being carried out for 30 locations (2 samples taken for each location) within the Cameron Highlands Catchment. Sieve analysis was carried out for the soil samples taken and subsequently the input parameters from the results of tests being carried out were inserted into the Malaysian Nomograph for Calculation of Soil Erodibility Factor, $\mathrm{K}$ to determine the $\mathrm{K}$ factor ${ }^{[7]}$. Interpolation of $\mathrm{K}$ values using IDRISI (Geographical Information System, GIS) programme would produce the K Factor Map needed for the purpose of database development of the study area. 


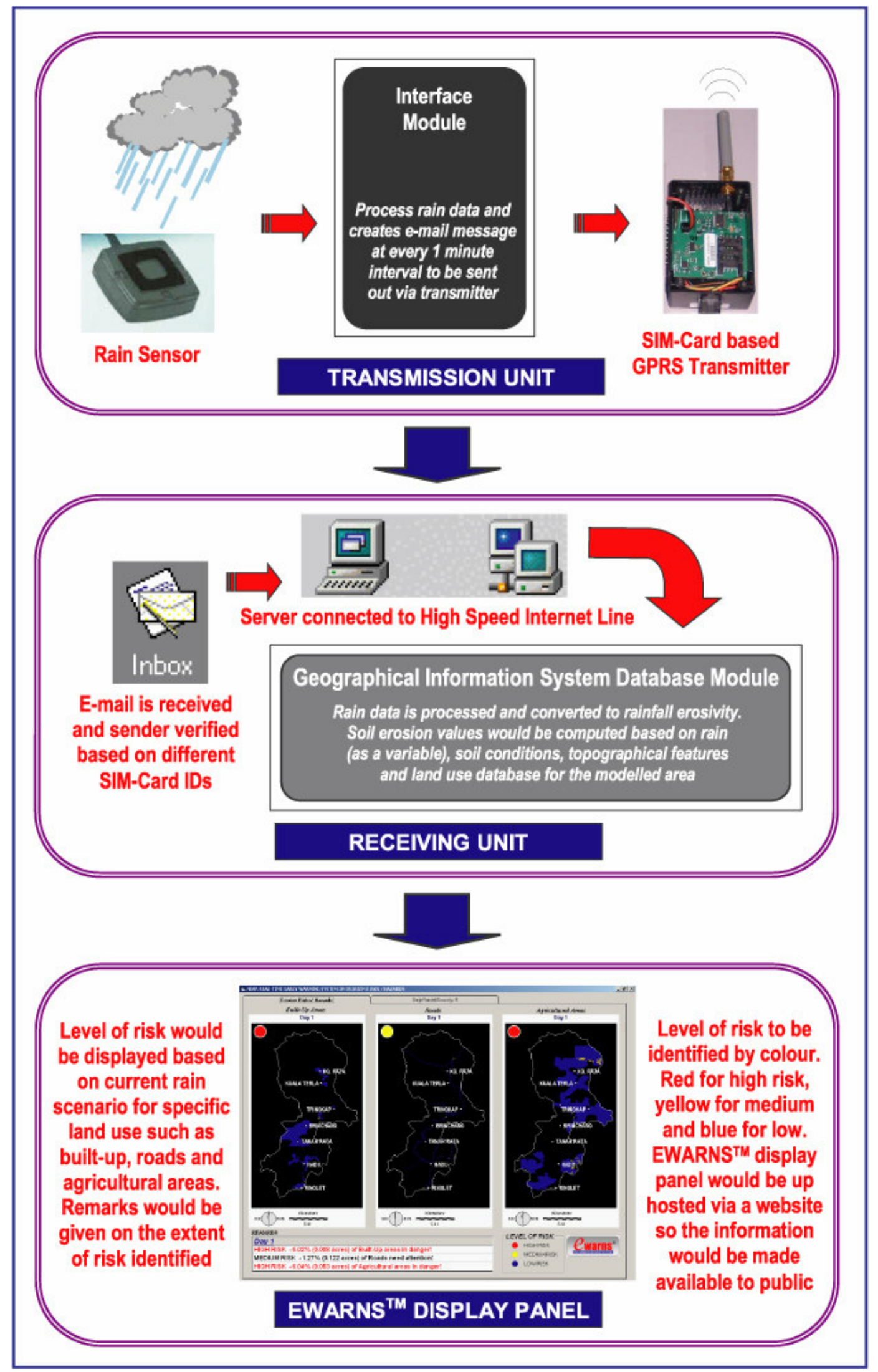

Fig. 4: Operation of EWARNS ${ }^{\mathrm{TM}}$ real-time early warning system on erosion hazards 

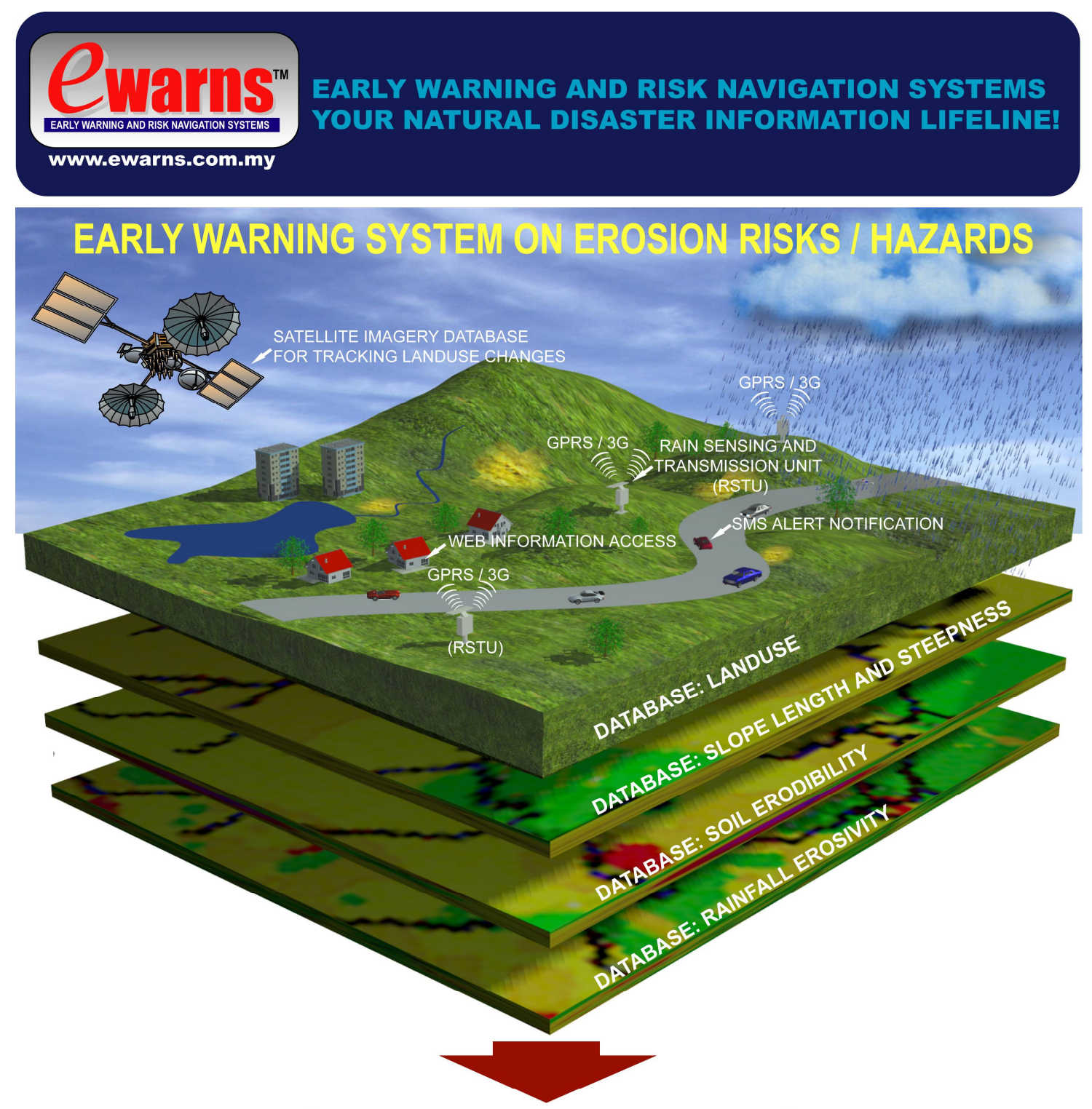

EWARNS TM CENTRALIZED MONITORING STATION (INFORMATION PROCESSED AND DISSEMINATED)

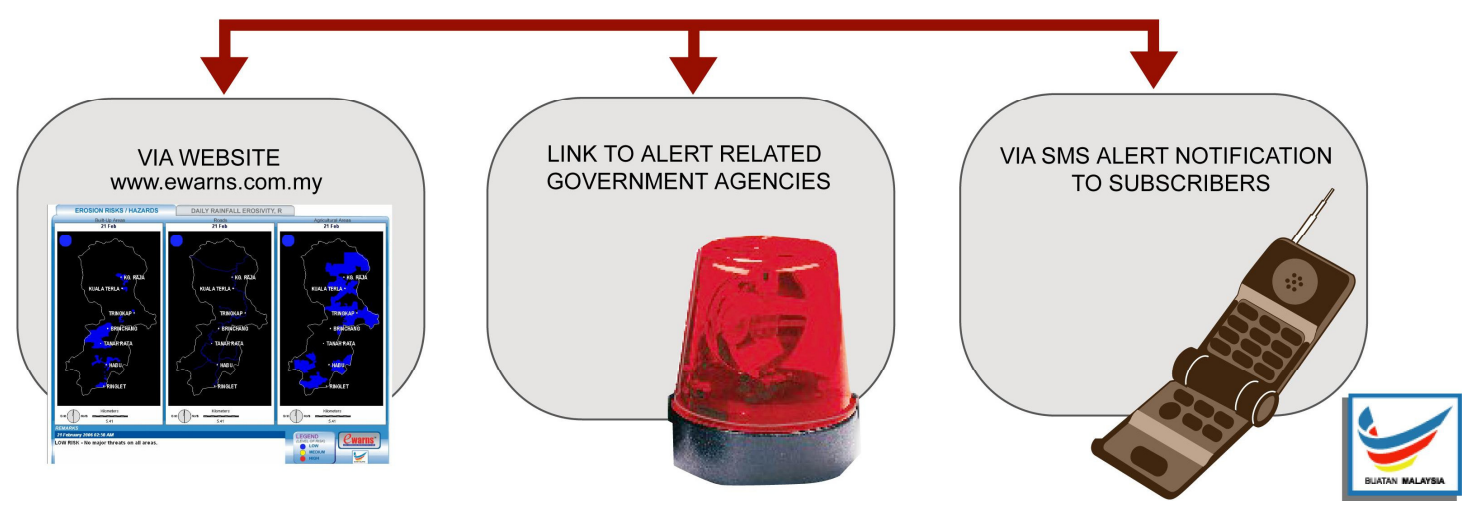

Fig. 5: Graphical interpretation of the operational phase for EWARNS ${ }^{\mathrm{TM}}$ real-time early warning system on erosion risks / hazards 


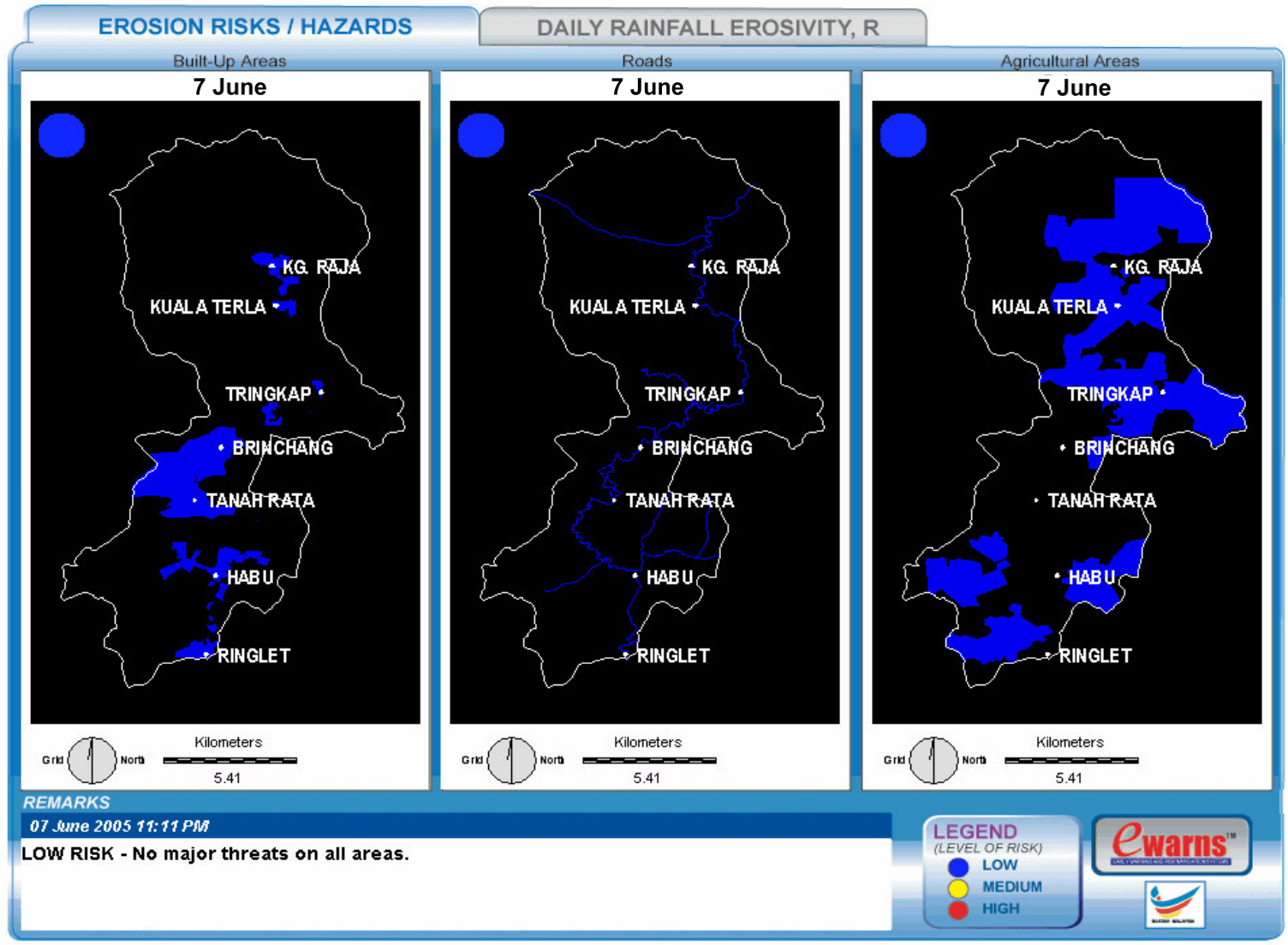

Fig. 6: Real-Time EWARNS ${ }^{\mathrm{TM}}$ display panel on erosion hazards

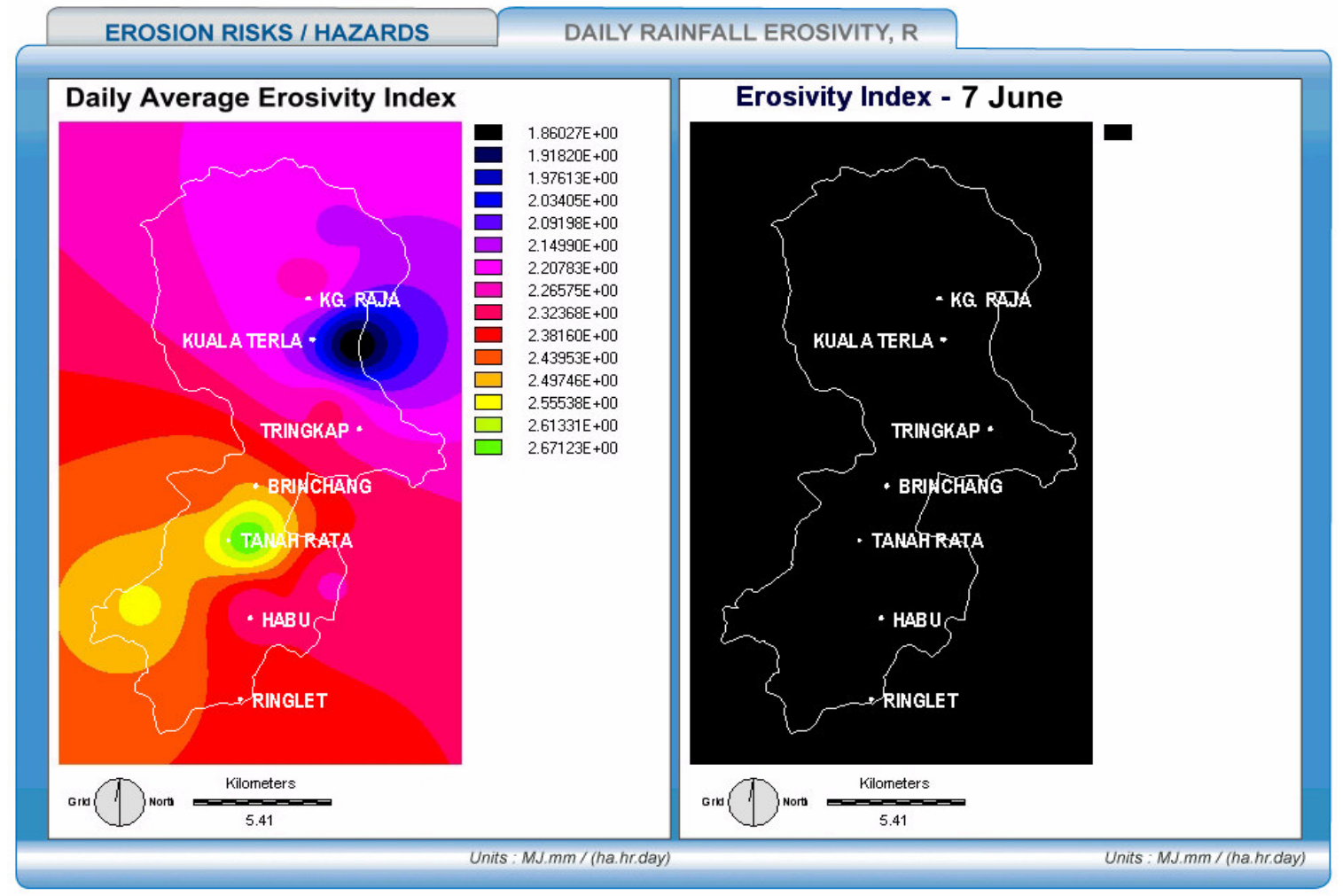

Fig. 7: $\quad$ EWARNS ${ }^{\mathrm{TM}}$ display panel on rainfall erosivity 


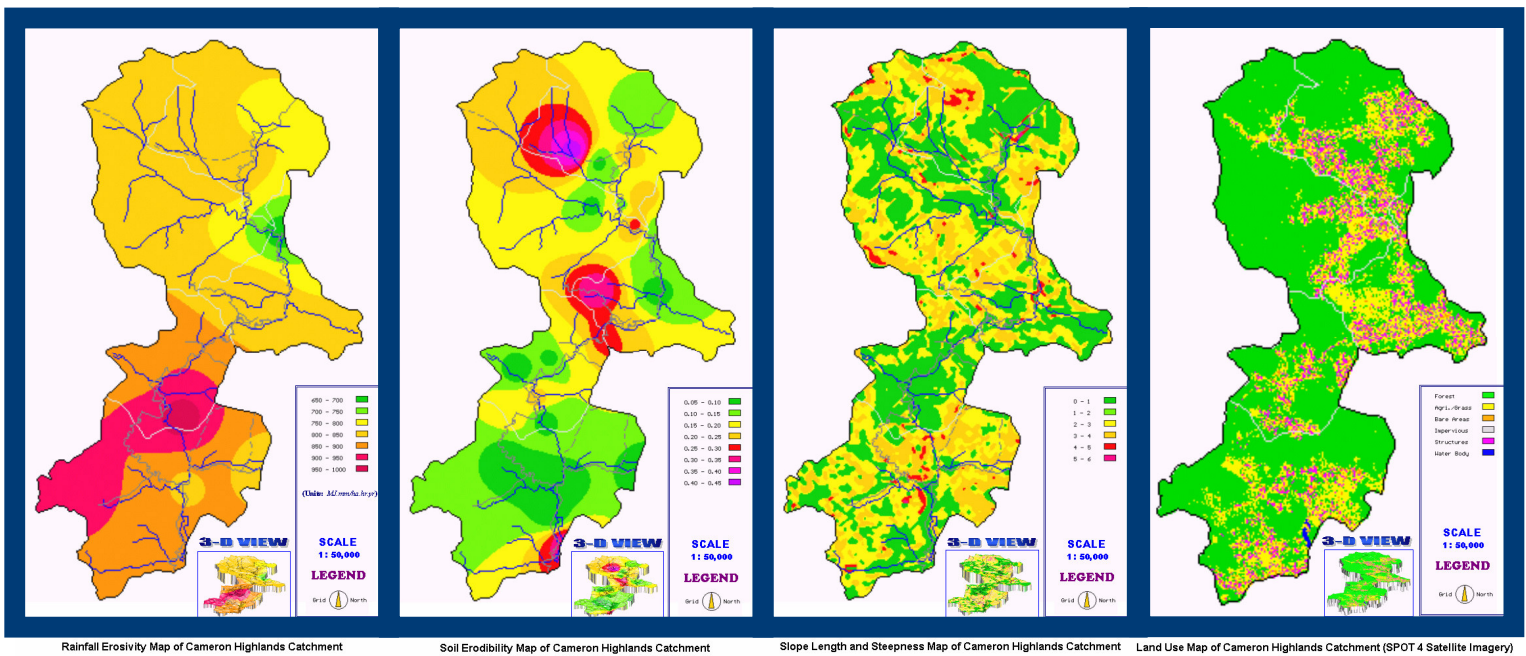

Fig. 8: Baseline data acquisition and GIS database development

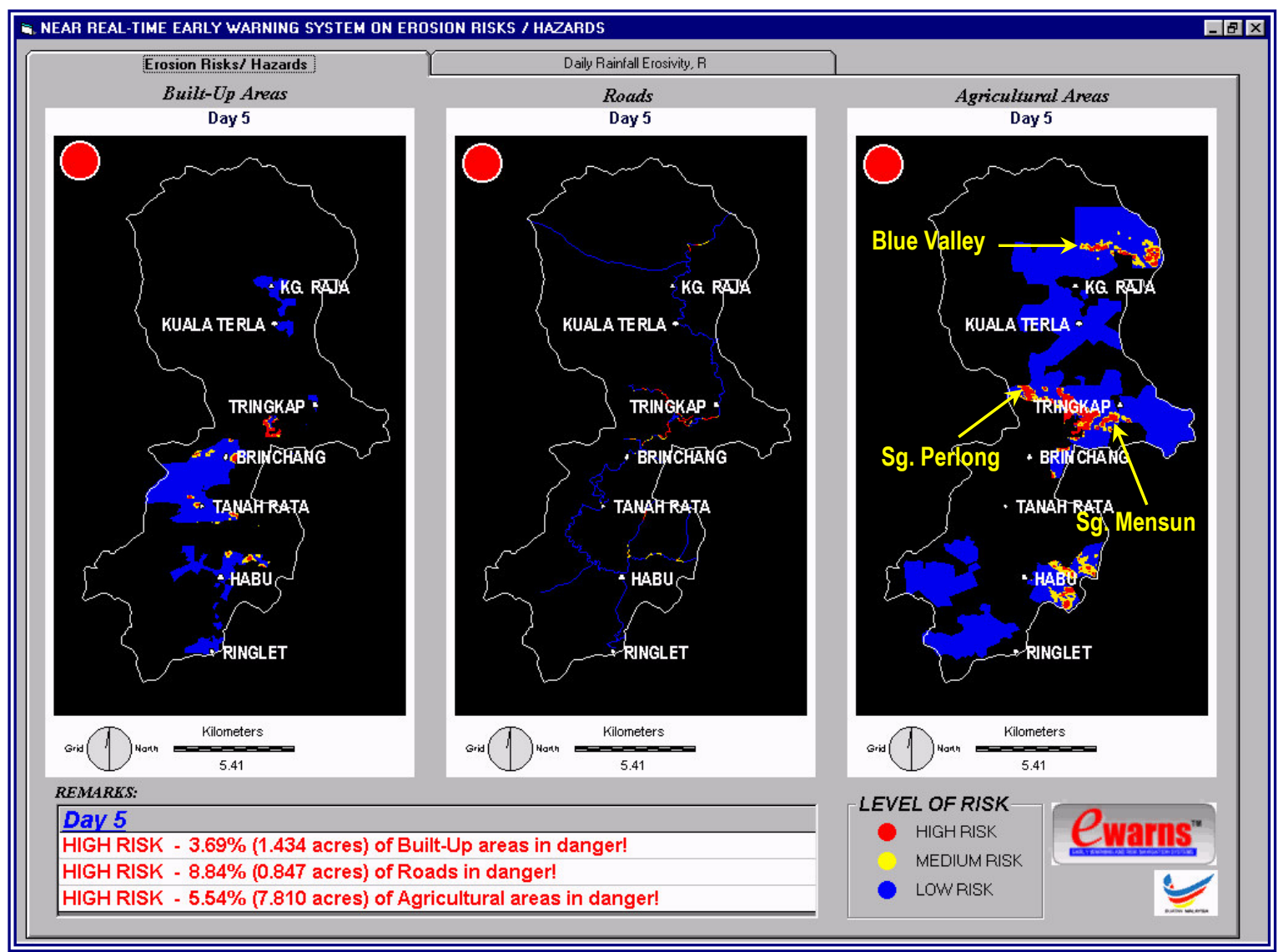

Fig. 9: Simulated EWARNS ${ }^{\mathrm{TM}}$ Display Panel observation on $5^{\text {th }}$ January 2003

The Slope Length and Steepness, LS, is acquired by digitizing the contours from the Cameron Highlands Topographical Map (Sheet 74) with a scale of 1:50,000. The LS factor is then calculated by using the "slope analysis" programme in IDRISI, which is based on the USLE's graph (standard conditions are 9\% slope and length of $22.1 \mathrm{~m})$. By entering the graph for other values of slope steepness and length, the LS ratio that is to be applied in the USLE can be obtained. Interpolation of the slope length and steepness using GIS would produce the LS Factor Map. The Land Use Management, CP, for the study area would take into consideration the three land use scenarios as comparison, namely: 
* Worst Case Scenario

* Land Use according to Structure Plan

* Land Use based on SPOT 4 Satellite Imagery

The worst-case scenario would be based on the assumption that the whole catchment area is cleared, whereas the land use for Structure Plan would be based on the MDCH's Structure Plan (1995 - 2020). The SPOT 4 Satellite Imagery (taken on the $7^{\text {th }}$ July 2002), which was acquired from Malaysian Centre for Remote Sensing (MACRES), indicates the current land use situation.

The database development of rainfall, soil, topographical and land use information for the area is as shown in Fig. 8. This is crucial, as the early warning system requires the latest data to ensure the predicted level of risk to achieve the best accuracy possible. As for rainfall data, even though this information would subsequently be transmitted by the RSTU in real-time, trial-runs on the system would be required using historical daily rainfall data acquired from the existing rainfall stations within the Cameron Highlands Catchment for purpose of programme simulation and correlation with reported incidences.

Verification of the early warning system: A reported incidence of heavy rain and subsequent landslides occurred within Cameron Highlands Catchment on $5^{\text {th }}$ January 2003 (simulation Day 5). During this incident, rain on that day was heavier than usual and possibly the highest for the year 2003, triggering landslides and soil erosion occurrences on various agricultural farms within Cameron Highlands as well as cutting off access road between Brinchang and $\mathrm{Kg}$. Raja. Simulation of maximum erosivity index recorded was 62 MJ.mm/(ha.hr.day) and EWARNS ${ }^{\mathrm{TM}}$ warning signal (high risk) was issued for all the areas of interest (builtup, roads and agriculture) as shown in Fig. 9.

\section{CONCLUSION}

In conclusion, the development of a near real-time early warning system on erosion hazards would certainly benefit various parties including the local authorities, relevant government agencies and the public, consisting of motorists, tourists, hoteliers and farmers in highland areas, as it would serve as an early warning in the case of any potential erosion risks or possible landslide occurrences. The EWARNS ${ }^{\mathrm{TM}}$ early warning system, which consists of the transmission unit, receiving unit and EWARNS ${ }^{\mathrm{TM}}$ display panel, is hoped to achieve its purpose in providing early warning and alerting the authorities as well as the public in general of the potential high erosion risk areas within the affected areas once there are incidences of heavy downpour. Finally, with the introduction of this early warning system, it is hoped that better monitoring of the study area, Cameron Highlands Catchment could be provided and more attention should be paid to control indiscriminate or illegal clearing of areas with a potentially high erosion risk. Therefore, preventive and mitigation measures could be initiated early and duly enforced.

\section{ACKNOWLEDGEMENT}

Special thanks are extended to various parties for their assistance and contribution, which include:

Malaysian Meteorological Department, Malaysian Centre for Remote Sensing, SSJCH Generation Division, Tenaga Nasional Berhad, Hydrology and Water Resources Division, Department of Irrigation and Drainage Malaysia.

\section{REFERENCES}

1. Rubber Research Institute of Malaysia, 1980. Soil Erosion and Conservation in Peninsular Malaysia, Kuala Lumpur, Malaysia.

2. Beasley, R.P., 1972. Erosion and Sediment Pollution Control, Iowa State Univ. Press, USA.

3. Morgan, R.P.C., 1993. Soil Erosion and Conservation, Longman Scientific and Technical, New York, USA.

4. Wischmeier, W.H. and D.D. Smith, 1978. Predicting Rainfall Erosion Losses - A Guide to Conservation Planning. USDA, Agriculture Handbook No. 537, USA.

5. Roslan, Z.A., 1992. Ph.D dissertation submitted to the United Graduate School of Agriculture Science, Kagoshima University, Japan.

6. Hudson, N.W., 1979. Soil Conservation, Cornell Univ. Press, USA.

7. Tew, K.H., 1996. Production of Malaysian Soil Erodibility Nomograph in Relation to Soil Erosions Issues, M. Eng. Thesis Dissertation, UTM Skudai, Johor Darul Takzim, Malaysia. 